\title{
Optical properties of inorganic AgSb recording thin film
}

\author{
Y. H. Fang, P. C. Kuo, ${ }^{\text {a) }}$ and P. W. Chen \\ Institute of Materials Science and Engineering, National Taiwan University, Taipei 106, Taiwan \\ Wei-Chih Hsu \\ Photovoltaics Technology Center, Industrial Technology Research Institute, Hsinchu 310, Taiwan \\ C. Y. Chou and T. H. Wu \\ Institute of Materials Science and Engineering, National Taiwan University, Taipei 106, Taiwan
}

(Received 3 March 2006; accepted 27 May 2006; published online 30 June 2006)

\begin{abstract}
$50 \mathrm{~nm} \mathrm{Ag}{ }_{1-x} \mathrm{Sb}_{x}(x=10.8-25.5)$ thin films were prepared by magnetron sputtering. Thermal analysis shows that the phase change occurs around $250{ }^{\circ} \mathrm{C}$. The optical property analysis show that the as-deposited $\mathrm{Ag}_{80.9} \mathrm{Sb}_{19.1}$ films have high reflectivity of about 62\%-73\%. After heat treatment at $300{ }^{\circ} \mathrm{C}$, the contrast of $\mathrm{Ag}_{80.9} \mathrm{Sb}_{19.1}$ film is $12.5 \%-17 \%$ for wavelengths between 400 and $800 \mathrm{~nm}$. Dynamic test shows that using the $\mathrm{Ag}_{80.9} \mathrm{Sb}_{19.1}$ film as the memory layer of write once optical disk, a carrier-to-noise ratio of about $45 \mathrm{~dB}$ can be achieved at $\lambda=657 \mathrm{~nm}$, numerical aperture of 0.65 , and a linear velocity of $3.5 \mathrm{~m} / \mathrm{s}$. (C) 2006 American Institute of Physics. [DOI: 10.1063/1.2218774]
\end{abstract}

As present, the recording layer of write once and read many (WORM) optical disk is usually made of organic dyes. ${ }^{1,2}$ Since the wavelength range that can be absorbed by organic dyes is narrow, absorption by organic materials cannot fulfill the requirements of high density optical memory. ${ }^{3}$ Again, it is not easy to get a uniform layer of the organic dye in the high density recording disk. Recently, inorganic materials were investigated to replace organic dyes in blue ray disks and digital versatile disks (DVDs).

In 1993, Baba et al. ${ }^{4,5}$ studied the possibility of applying an inorganic metal thin film including $\mathrm{Au}, \mathrm{Ag}, \mathrm{Cu}$, and $\mathrm{Al}$ to WORM optical disks. When the thickness of the metal film is thinner than $10 \mathrm{~nm}$, the as-deposited film is formed of nanoclusters. It would have high reflectivity and absorption. Since only the nanostructure of the metal thin film is changed when the metal film absorbs laser energy, it would not take long time in writing. They found that Ag-based metal thin film has high reflectivity and high reflectivity change. On the other hand, it has been known that $\mathrm{Sb}$ has high crystallization rate. ${ }^{6}$ We expect that the combination of $\mathrm{Ag}$ and $\mathrm{Sb}$ may have high reflectivity and high crystallization rate. In this work, we used a Ag-based material in the form of $\mathrm{Ag}_{1-x} \mathrm{Sb}_{x}$ films, measured its optical properties, and investigated the possibilities of applying it to the WORM disk.

For analysis of the optical properties, a $\mathrm{ZnS}-\mathrm{SiO}_{2}$ protecting layer with a thickness of $1000 \AA$ was deposited by radio frequency (rf) magnetron sputtering on naturally oxidized Si (100) wafer and Marienfeld cover glass. The $\mathrm{Ag}_{1-x} \mathrm{Sb}_{x}$ recording films $(x=10-26$ at. \%) with thickness of $1000 \AA$ were deposited on $\mathrm{ZnS}-\mathrm{SiO}_{2}$ on the protecting layer by rf cosputtering of $\mathrm{Ag}$ and $\mathrm{Sb}$ targets. For dynamic tests, a Ag (1000 А) reflecting layer was further deposited on the $\mathrm{Ag}_{1-x} \mathrm{Sb}_{x}$ layer by rf magnetron sputtering with an Ar pressure of 3 mTorr. After deposition, the films were annealed at various temperatures in vacuum for $5.5 \mathrm{~min}$ and then quenched in ice water. The crystal structures of the films were investigated by x-ray diffraction (XRD) with $\mathrm{Cu} K \alpha$ radiation and field emission gun transmission electron mi-

a) Author to whom correspondence should be addressed; FAX: +886-223634562; electronic mail: pckuo@ntu.edu.tw croscopy (FEG-TEM). Composition of the film was determined from the energy dispersive spectrum (EDS). The thickness of the film was measured by $\alpha$ step and atomic force microscope (AFM). Dynamic tests of disks were carried on a Pulstec DDU-1000 machine.

Figure 1 shows the relationship between reflectivity and temperature of the as-deposited $\mathrm{Ag}_{1-x} \mathrm{Sb}_{x}$ films at a heating rate of $50{ }^{\circ} \mathrm{C} / \mathrm{min}$. Two reflectivity changes are clearly observed in all the films as the temperature is increased from 100 to $400{ }^{\circ} \mathrm{C}$. It indicates that the first phase transition temperature of $\mathrm{Ag}_{1-x} \mathrm{Sb}_{x}$ films is around $250{ }^{\circ} \mathrm{C}$. Moreover, a higher reflectivity is observed when the $\mathrm{Sb}$ content of the film is lower than 19.1 at. \%. But the films with Sb content lower than 19.1 at. \% have lower contrast around $250{ }^{\circ} \mathrm{C}$ than that of Sb content higher than 19.1 at. \%. However, only the reflectivity of $\mathrm{Ag}_{80.9} \mathrm{Sb}_{19.1}$ film is stable lower and higher the phase transition temperature. Therefore, the $\mathrm{Ag}_{80.9} \mathrm{Sb}_{19.1}$ film will be examined in detail.

Figures 2(a) and 2(b) show the reflectivity and contrast of the as-deposited and annealed $\mathrm{Ag}_{80.9} \mathrm{Sb}_{19.1}$ films at various laser beam wavelengths, and annealing temperatures of 300 and $350{ }^{\circ} \mathrm{C}$, respectively. The reflectivity of the $\mathrm{Ag}_{80.9} \mathrm{Sb}_{19.1}$ film is decreased after annealing at 300 or $350{ }^{\circ} \mathrm{C}$. From the $\mathrm{X}$-ray diffraction pattern (Fig. 3), we observed that the asdeposited $\mathrm{Ag}_{80.9} \mathrm{Sb}_{19.1}$ film has an orthorhombic $\varepsilon^{\prime}-\mathrm{AgSb}$

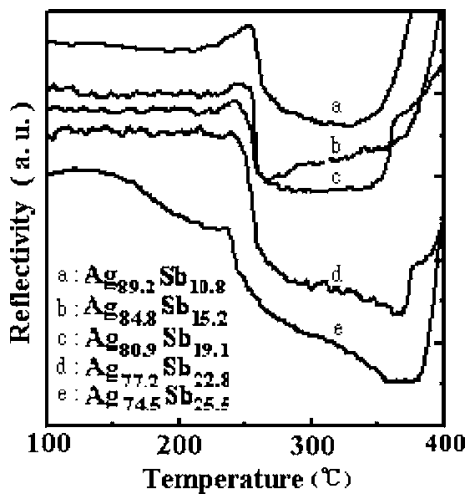

FIG. 1. Variation of reflectivity with temperature of the as-deposited $\mathrm{Ag}_{1-x} \mathrm{Sb}_{x}$ films. 


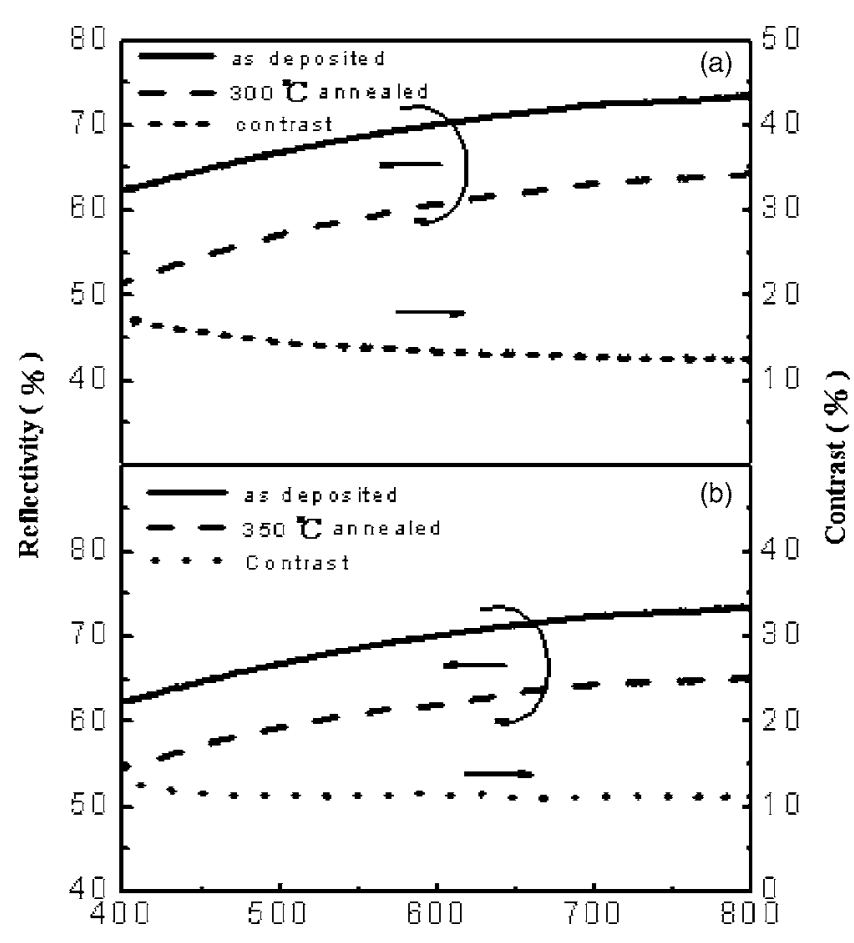

FIG. 2. Relationship among reflectivity, contrast, and laser beam wavelength of the as-deposited, (a) 300 and (b) $350{ }^{\circ} \mathrm{C}$ annealed $\mathrm{Ag}_{80.9} \mathrm{Sb}_{19.1}$ films.

crystalline structure. The orthorhombic structure is the cause of the optical anisotropy. By grain refining, the optical anisotropy could be reduced to avoid the difference of reflection from different grain orientations. ${ }^{7}$ Figures 4(a)-4(c) show the TEM images and electron diffraction patterns of the asdeposited, annealed at 300 and $350{ }^{\circ} \mathrm{C} \mathrm{Ag}_{80.9} \mathrm{Sb}_{19.1}$ films, respectively. From Fig. 4(a), it is found that the grain sizes are about 5-10 $\mathrm{nm}$ and the grains are uniform for the asdeposited film. The optical anisotropy is reduced due to this small and uniform grain size which leads to the large reflectivity of the as-deposited $\mathrm{Ag}_{80.9} \mathrm{Sb}_{19.1}$ film, as shown in Figs. 2(a) and 2(b). After the $\mathrm{Ag}_{80.9} \mathrm{Sb}_{19.1}$ films are annealed at 300 or $350{ }^{\circ} \mathrm{C}$, the grain sizes grow to $10-100 \mathrm{~nm}$. These nonuniform grain sizes would cause more optical anisotropy and lead to a reduction in the reflectivity of the film. Therefore, the reflectivity of the $\mathrm{Ag}_{80.9} \mathrm{Sb}_{19.1}$ film after annealing at 300 or $350{ }^{\circ} \mathrm{C}$ would be lower than the as-deposited film, as

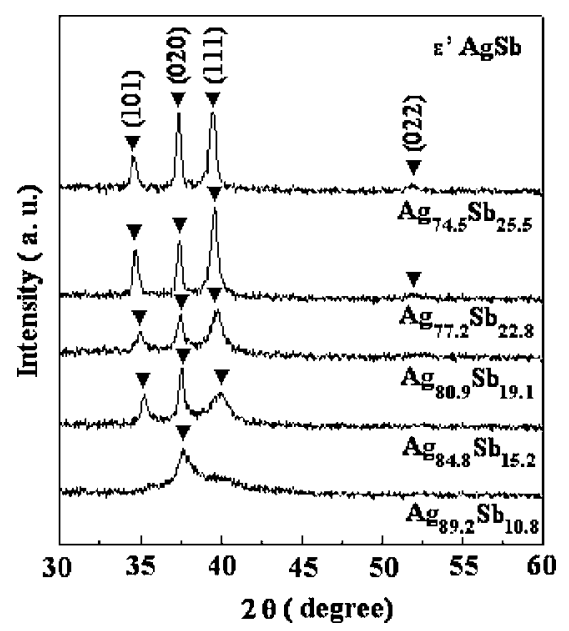

FIG. 3. X-ray diffraction patterns of various as-deposited $\mathrm{Ag}_{1-x} \mathrm{Sb}_{x}$ films.

Downloaded 08 Dec 2008 to 140.112.113.225. Redistribution subject to AlP license or copyright; see http://apl.aip.org/apl/copyright.jsp
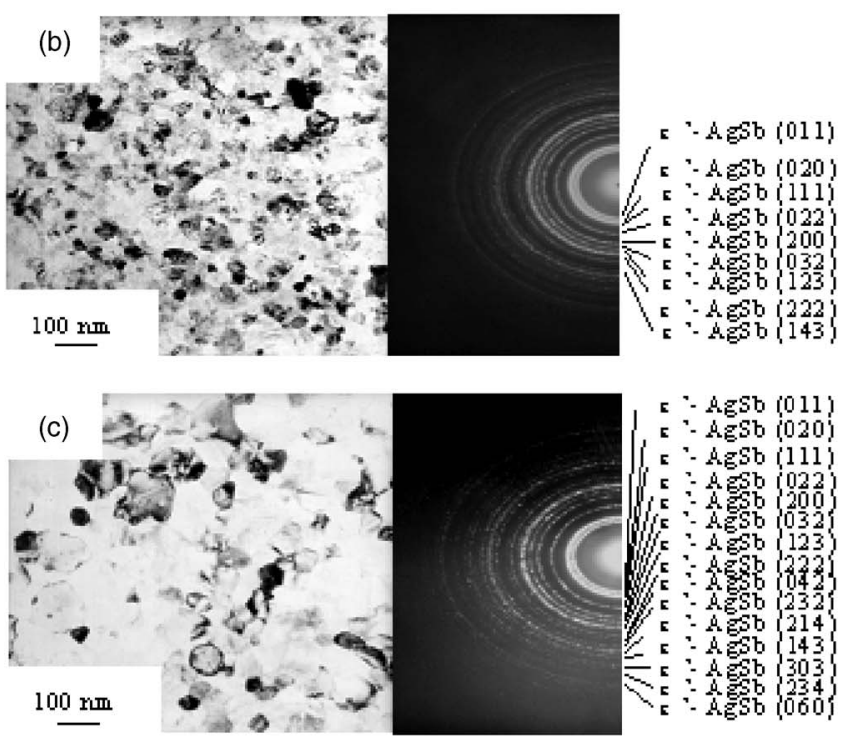

FIG. 4. TEM bright field image and diffraction pattern of the (a) asdeposited, (b) 300 and (c) $350{ }^{\circ} \mathrm{C}$ annealed $\mathrm{Ag}_{80.9} \mathrm{Sb}_{19.1}$ films.

shown in Figs. 2(a) and 2(b). The contrasts of the $\mathrm{Ag}_{80.9} \mathrm{Sb}_{19.1}$ films are about $12.5 \%-17 \%$ and $11 \%-12 \%$ in the wavelength between 400 and $800 \mathrm{~nm}$ for the films annealed at 300 and $350{ }^{\circ} \mathrm{C}$, respectively.

Since the $\mathrm{Ag}_{80.9} \mathrm{Sb}_{19.1}$ film has higher reflectivity, higher optical contrast, and suitable phase transition temperature, we take the $\mathrm{Ag}_{80.9} \mathrm{Sb}_{19.1}$ disk for dynamic tests. The dynamic test was conducted at $\lambda=657 \mathrm{~nm}$, numerical aperture (NA) $=0.65$, and DVD $1 \mathrm{X}$ and $14 T$. Figure 5 shows the relationship between the writing power and carrier-to-noise ratio (CNR). The critical writing power is about $3 \mathrm{~mW}$. A small recording area is formed when the writing power is smaller

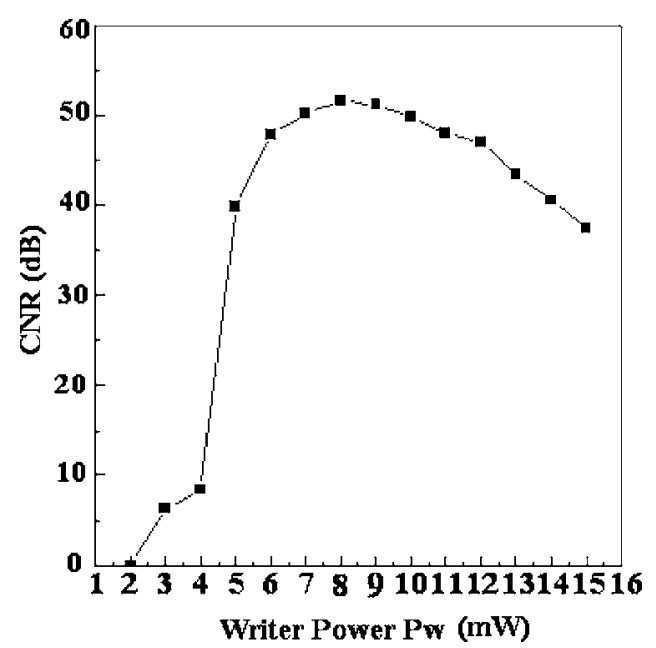

FIG. 5. Relationship between the writing power and carrier-to-noise ratio (2)

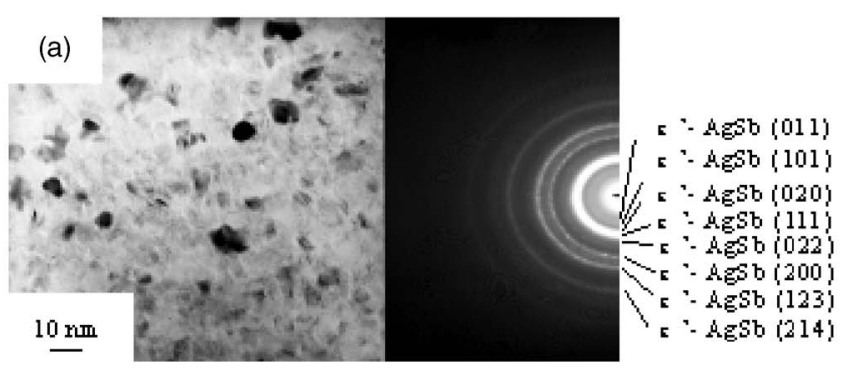


than $4 \mathrm{~mW}$. This leads to small CNR values (less than $10 \mathrm{~dB}$ ). If the writing power is in the range of $6-12 \mathrm{~mW}$, the CNR values are higher than $45 \mathrm{~dB}$ due to larger recording area. This is quite satisfactory for the requirements of the WORM optical disk. The reason why the CNR value decreases as the writing power is higher than $12 \mathrm{~mW}$ may be due to the distortion of the film structure of the disk at higher writing power. The distortion of film structure of the disk will increase the noise thus leading to a decrease in the CNR value.

To summarize, it is found that the as-deposited $\mathrm{Ag}_{80.9} \mathrm{Sb}_{19.1}$ film is well crystallized with a grain size of about $5-10 \mathrm{~nm}$, so that it has a large reflectivity value (about $62 \%-73 \%)$. Moreover, the $\mathrm{Ag}_{80.9} \mathrm{Sb}_{19.1}$ film possesses large optical contrast within the laser beam wavelength range of $400-800 \mathrm{~nm}$ and a large CNR value (about $45 \mathrm{~dB}$ ). This film is a promising material for WORM disk.

This work was supported by the National Science Council and Ministry of Economic Affairs of Taiwan through the NSC 94-2216-E-002-009 and 94-EC-17-A-08-S1-0006 grants, respectively.

${ }^{1}$ J. J. M. Ruigrok, R. Coehoorn, S. R. Cumpson, and H. W. Kesteren, J. Appl. Phys. 87, 5398 (2000).

${ }^{2}$ S. Miyanishi, K. Kojima, J. Sato, A. Takahashi, and K. Ohta, J. Appl. Phys. 93, 7801 (2003).

${ }^{3}$ T. Minemura, H. Andoh, and Y. Maeda, J. Appl. Phys. 63, 4632 (1989).

${ }^{4}$ K. Baba, K. Hayashi, and M. Miyagi, Electron. Lett. 29, 1948 (1993)

${ }^{5}$ K. Baba, K. Hayashi, and M. Miyagi, Proc. SPIE 2338, 175 (1994).

${ }^{6}$ K. Baba, Y. Ohkuma, T. Yonezawa, and M. Miyagi, Appl. Opt. 40, 2796 (2001).

${ }^{7}$ K. A. Rubin, Mater. Res. Soc. Symp. Proc. 230, 239 (1992). 